\title{
Bringing supply chain training opportunities closer to home-an experience with regional training institutes
}

\author{
Motomoke Eomba', Kim Peacock, Rebecca Alban \\ From The 2nd People that Deliver (2nd PtD) Global Conference on Human Resources in Supply Chain \\ Management \\ Copenhagen, Denmark. 29-30 October 2014
}

\section{Background}

Since 1994, USAID and JSI have provided introductory supply chain courses for international audiences. As demand for these courses continued to grow, it became apparent that local delivery would increase the cost-effectiveness and sustainability of global SCM trainings. Starting in 2007, the USAID | DELIVER PROJECT built the capacity of four Regional Training Institutes (RTIs) that now offer high quality supply chain courses to an international audience in three languages (English, Spanish, and French).

\section{Method}

The project developed detailed selection criteria to use when surveying and selecting RTIs, then trained and mentored the selected institutes in SCM, training/facilitation, marketing, and consulting. These capacity building interventions enabled the RTIs to design, package, price, market, and deliver capacity building programs; provide targeted technical assistance; and apply business savvy to their management and development activities.

\section{Results}

Over time, the RTIs have evolved as leaders in training for SCM and logistics; they continue to offer high-quality training solutions in developing countries. Based in Peru, Tanzania, Burkina Faso, and South Africa, the RTIs leveraged local talent to provide training in commodity security and supply chain management of health commodities to the areas that needed it most. Today, the RTIs are either working entirely on their own, or with minimal technical

* Correspondence: meomba@jsi.com

USAID | DELIVER PROJECT, John Snow Inc., Washington DC, USA assistance from the project. Financial support for trainings comes mainly from participants' fees with diminishing support from USAID funds.

\section{Discussion}

Project experience with the RTIs demonstrates that "facilitated outsourcing" of SCM trainings to regional training institutes can be a successful intervention to increase global supply chain training opportunities. While some objectives were met with quick success, others required significant technical assistance. RTIs have been successful in: recovering costs with their pricing structures, building consulting skills, forming a culture of entrepreneurship, and delivering high quality, highly rated courses. Challenges include: drafting adequate marketing plans to ensure sufficient enrolment, and ensuring ongoing quality control of courses.

\section{Lessons learned}

Positive results include: reduced donor costs, creation of local opportunities for SCM professionals, and more participants trained each year. Specific attention must be given to: course pricing flexibility to meet market demands, formal evaluation/cost analysis of RTIs for evidence-building, and potential market saturation.

Published: 17 December 2014

doi:10.1186/2052-3211-7-S1-015

Cite this article as: Eomba et al.: Bringing supply chain training opportunities closer to home-an experience with regional training institutes. Journal of Pharmaceutical Policy and Practice 2014 7(Suppl 1):015.
() Biomed Central

(c) 2014 Eomba et al; licensee BioMed Central Ltd. This is an Open Access article distributed under the terms of the Creative Commons Attribution License (http://creativecommons.org/licenses/by/4.0), which permits unrestricted use, distribution, and reproduction in any medium, provided the original work is properly cited. The Creative Commons Public Domain Dedication waiver (http:// creativecommons.org/publicdomain/zero/1.0/) applies to the data made available in this article, unless otherwise stated. 